\title{
COLHENDO OS FRUTOS: REPENSAR AS CONDIÇÕES DE GOVERNANÇA
}

Hoje, uma criança não será atendida no posto de saúde. Uma família não terá água potável, nem energia elétrica. Um pequeno empresário pagará propina a um agente-fiscal sanitário a fim de evitar penalidades maiores por violações que sequer existiram, enquanto um gestor público subornará certo fornecedor para que este receba o pagamento pelos serviços que prestou. Um servidor com evidências concretas sobre pagamentos ilegais no governo irá se questionar porque seu superior não demonstra interesse em sua história. Um investidor local com planos para melhorar determinada comunidade terá uma licença ou autorização essencial negada - novamente. Cenários como estes e muitos outros irão ocorrer em todas as sociedades, ricas ou pobres, democráticas ou totalitárias. ${ }^{314}$

Nos últimos tempos, tais episódios até estampam um número maior de manchetes, e alguns infratores e beneficiários dos esquemas mais graúdos amargam longos períodos atrás das grades. Mesmo assim, os cenários se repetem, dia após dia.

Podemos assumir que essa condição será inteiramente superada identificando os responsáveis por cada uma das situaçōes acima descritas, fazendo com que respondam pelos seus atos, ou aprovando leis que endureçam as penalidades atribuídas a tais ilícitos. Neste caso, estaríamos confessando a nossa incapacidade de ir além da extração da maçã-podre, para explorar a verdadeira e mais complexa dimensão do problema.

314 JOHNSTON, Michael. Corruption, contention and reform. The power of deep democratization. Cambridge University Press, 2014. 
- Finanças públicas: travessia entre o passado e o futuro

A corrupção não deve ser examinada apenas como uma atitude individual, restrita à tradicional definição associada ao abuso do ofício público para obtenção de vantagens privadas, numa perspectiva limitada à relação entre agente-principal, como se os países considerados "limpos" nos índices de percepção da corrupção se diferenciassem dos que estão na base da lista, simplesmente pelo número agregado de pessoas que cometem atos corruptos, e não pela qualidade de seus contextos institucionais e das regras do jogo postas. Inadiável, então, considerar um ângulo mais amplo da corrupção, como mazela social que é, fruto de um modelo clientelista de distribuição de recursos e poderes entre os cidadãos, que sobrevive e evolui em determinadas condições ideais de temperatura e pressão. Referido modelo é identificado principalmente pelo aprofundamento das iniquidades, ao privilegiar caçadores de renda (rent-seeking) e conceder privilégios jurídicos que geram impunidade, pela opacidade, ao limitar a competitividade e as possibilidades de controle social, e pela irracionalidade, ao distorcer os dispêndios e prioridades do governo, além de quebrar a autonomia das instituições sociais.

Observar a origem remota e o desenvolvimento contínuo da patronagem no Brasil, o modo como isso moldou nossa sociedade contemporânea e o tipo de interação entre as pessoas e o Estado, conforme exposto amiúde nas obras de Raymundo Faoro, Gilberto Freyre e Celso Furtado, ajuda a compreender porque a segunda visão deveria prevalecer. Ademais, o sofrimento das contas públicas, materializado, por exemplo, no fechamento de postos de saúde e no atraso de salários e aposentadorias, desenvolveu na população a consciência de que os recursos originalmente destinados à aplicação do bem-estar comum foram tomados por grupos específicos.

A propósito, os dados do latinobarômetro de 2017, mostrando que a percepção da corrupção está significativamente associada à importância das conexões políticas (favoritismo, clientelismo e nepotismo), e a forte crença de que se governa para alguns poucos poderosos em seu próprio benefício (o Brasil ocupa, aliás, a primeira posição neste quesito entre os países da América Latina) constitui forte indicativo de que a visão sistêmica é extremamente importante.

Por isso é que, reforçando a premissa inicial deste livro, abordagens que enfoquem somente a penalização individual e o endurecimento das penas podem até fornecer um alento efêmero à sociedade, criando a impressão de que "se está fazendo algo concreto", de forma rápida e eficiente, mas serão insuficientes para converter o ciclo pernicioso em um ciclo virtuoso de universalismo ético e bom-governo. $\mathrm{O}$ sucesso das campanhas contra a corrupção não deveria ser mensurado apenas pelo número de sanções impostas no curto-prazo, senão também pelos efeitos mais longevos que exerce nas instituiçōes e na cultura. 
Precisamos, pois, repensar as bases sobre as quais atuam nossas instituições, não apenas no tocante à capacidade dos governos de atender as demandas dos cidadãos, mas à habilidade de produzir políticas íntegras e eficientes, aproximando a população do Estado e oferecendo soluções efetivas à corrupção e à iniquidade. Noutros termos, mudar o ambiente onde a árvore floresce, para que ao invés de vivermos recolhendo frutos podres, ela apenas pare de produzi-los.

Ao prover explicações sobre porquê determinadas nações fracassam, Daren Acemoglu e James A. Robinson reforçam este ponto ao argumentar que más instituições são produto de sistemas políticos que geram ganhos privados para as elites, de modo que as trocas baseadas na corrupção aprisionam o país numa espécie de armadilha de renda média.

Associo a questão à própria qualidade da governança democrática, compreendida justamente como as regras formais e informais (institucionalidade) que determinam como serão alocados os recursos na sociedade - quem fica com o quê em determinada política. Em outras palavras, estabelece as regras sob as quais o jogo é jogado. Problema perene na agenda social brasileira é como melhorar essa tal de governabilidade, promovendo a limpeza do patrimonialismo e o desenvolvimento inclusivo, sem ter que apelar a líderes populistas ou demagogos de espírito autoritário que prometam a salvação nacional. Salvação, sim, salvadores, não, como diria Ruy Barbosa. Nós queremos é sair do atoleiro moral e acertar o passo das nossas instituiçōes, resgatando a tradição republicana das virtudes cívicas, com uma compreensão clara sobre como defender o interesse público da ganância privada. ${ }^{315}$

Como disse Claude-Adrien Helvécios, em carta à Montesquieu, datada de 1748, só conheço duas espécies de governos: os bons e os maus. Os bons que estão ainda por fazer; os maus, em que toda arte consiste, por diferentes meios, em passar o dinheiro da parte governada à bolsa da parte governante.

Inevitável não se alongar neste momento para explicar a premissa institucional. Por isso, vá me desculpando o leitor.

Esta preocupação central com o bom funcionamento das instituições do Estado republicano, aliás, foi o mote para a criação do movimento que propõe uma releitura dos valores republicanos - o neorrepublicanismo, cujo principal expoente é o filósofo irlandês Philip Pettit. ${ }^{316}$ Calcado na ideia de liberdade como ausência

315 GUIMARÃES, Juarez. Sociedade civil e corrupção: crítica à razão liberal. In: AVRITZER, L.; FILGUEIRAS, F. (Org.). Corrupção e sistema político no Brasil. Rio de Janeiro: Civilização Brasileira, 2011, p. 88-89.

316 PETTIT, Philip. Republicanism: a theory of freedom and government. Oxford: Claredon Press, 2002. 
de dominação arbitrária, ou seja, de utilização da máquina estatal para perpetuação de privilégios injustos, Pettit propõe um tipo de democracia que chama de contestatória, pois assente na contestação permanente dos governantes. Enfatiza, bem assim, a necessidade de canais institucionais que permitam aos cidadãos questionarem, desafiarem e escrutinarem as políticas adotadas pelo governo e exigirem maior accountability no trato dos interesses públicos. Em suma, o que a visão moderna do republicanismo prega é justamente a evolução da governança, de modo que as decisões públicas sejam tomadas em bases que impeçam a corrupção e o desperdício. Vale rememorar o que dissemos no início do livro, que tais problemas são o resultado inescapável de uma governança frágil.

Parto do seguinte pressuposto: a qualidade da governança está assentada no nível de abertura dos governos democráticos. Ao falar sobre abertura, ${ }^{317}$ estou me referindo à aderência que as ações e políticas têm, primeiro, com a exigência de deliberação racional, ou seja, de consideração das múltiplas vozes que vêm da sociedade na busca contínua de legitimidade através do consenso (Habermas) e, segundo, com a necessidade de que esta deliberação ocorra em virtude da transparência inteligível e irrestrita dos dados públicos, possibilitando o escrutínio (accountability) permanente dos cidadãos, por si mesmos ou por intermédio de agências de vigilância especializadas (tribunais de contas, ministério público etc.), questionando e controlando as decisões adotadas pelos poderes públicos.

Destaco, portanto, três valores-condição principais associados à ideia republicana de governança e que serão explorados amiúde: transparência, participação e accountability.

Pode-se associar esse conjunto de condiçóes à ideia de representação alargada, de Stéfano Rodotà, ${ }^{318}$ ou à democracia de apropriação da qual fala Pierre Rosanvallón, ${ }^{319}$ constituída a partir dos postulados de legibilidade, responsabilidade e reatividade. No entanto, acredito que essas características estão mais próximas à noção de governo aberto (open government), cujos compromissos estão vinculados

317 Uma representação semelhante à noção de abertura empregada neste livro é utilizada por Robert Dahl, ao falar da contestabilidade, como pressuposto ou condição para o funcionamento adequado das poliarquias. (DAHL, Robert. A. Polyarchy: participation and opposition. Yale University Press, 1971).

318 RODOTÀ, Stéfano apud NOGUEIRA, Marco Aurélio. Governabilidade democrática progressiva. Lua Nova [online], n. 36, 1995.

319 ROSANVALLÓN, Pierre. El buen gobierno. Buenos Aires: Manantial, 2015: "pelo seu caráter descentralizado e multiforme, a democracia de apropriação está muito menos exposta às possibilidades de corrupção" (Tradução livre). 
justamente à necessidade de aumentar a disponibilidade de informação sobre as ações governamentais, apoiar a participação ampla do cidadão, aplicar standards de integridade e prestação de contas aos governantes. Este modelo que propõe, ao fim e ao cabo, renovar os canais pelos quais a sociedade se relaciona com o Estado, reconhecendo a necessidade fundamental de se resguardar da apropriação imoral dos recursos, ainda que a maioria dos indivíduos não sejam corruptos, e estejam dispostos a atuar eticamente.

Daí porque preferi realizar o corte metodológico, abordando primeiro os aspectos éticos (individual, corporativo e público) e a transformação dos valores da sociedade. As instituições podem até funcionar bem num contexto de governança adequada, porém, sem uma cultura de integridade e valores disseminada, basta um lapso de fragilidade para que apareçam oportunidades de corrupção, que não serão desprezadas por agentes imorais. Por outro lado, somente o apelo ético é insuficiente, sem instituições abertas e eficientes, caso contrário, a corrupção estará rapidamente disseminada entre os cidadãos, que irão se justificar (ou pelo menos tentarem se convencer) afirmando que são morais e éticos, mas estão inseridos num sistema corrompido. Civismo cartesiano não cola!

Além disso, para o bem ou para o mal, vale rememorar que o comportamento dos cidadãos - e a sua noção do que corresponde à conduta íntegra - é fortemente influenciado pela realidade social e pelas condutas similares percebidas ao seu redor. A percepção geral de que todos fazem assim, ou seja, a conformidade social, tende a favorecer o status quo, de modo que, em sociedades onde as próprias regras do jogo favorecem grupos específicos de poder, poucas pessoas irão se comportar de forma diferente. Elas sabem que uma ação honesta ou cooperativa terá pouco efeito se tomada sozinha ao invés de coletivamente, preferindo buscar o seu quinhão no lote de privilégios governamentais. Essa tendência à reprodução dos padrões de organização social e das regras de governança é o que pesquisadores chamam de equilíbrio - positivo ou negativo, que dificilmente se altera a partir de ações pontuais.

Há que se induzir um senso de eficiência que mobilize os indivíduos em favor da mudança das regras do jogo. A integridade se converterá em instituição (uma norma endossada pela maioria) ao invés de simples ideologia, quando uma parte significativa da sociedade compartilhar a crença na superioridade da integridade sobre o patrimonialismo como modelo de governança. Do contrário, materializa-se a advertência histórica de Maquiavel: um governo livre é inalcançável se os cidadãos são corruptos.

Antes de tudo, portanto, é necessária uma mudança de atitude, para depois cogitar soluçōes para o contexto institucional. Algumas portas só abrem por dentro. 
A questão principal, e aqui encerro a defesa da premissa institucional que estou tentando demonstrar, é entender que a evolução de um contexto A, onde prevalecem as formas patrimonialistas de distribuição do poder (equilíbrio negativo), para um contexto $\mathrm{B}$, onde a integridade e o governo aberto são regra (equilíbrio positivo) e a corrupção uma escandalosa exceção, envolve um esforço civilizatório, de modo que a sociedade consiga impor barreiras, prevenindo oportunidades à apropriação da coisa pública para servir a interesses particulares, em detrimento do bem coletivo. Importar instituições e medidas anticorrupção, ignorando o contexto em que atuam e a importância da ação coletiva em seu favor é não só contraproducente, como perigoso, na medida em que elas podem ser desvirtuadas para funcionar como anteparo à apropriação da coisa pública e à destruição de oponentes.

Deixo que John Stuart Mill explique melhor a tarefa proposta: um dos maiores perigos à democracia, bem como de todas as outras formas de governo, consiste nos interesses sinistros dos detentores do poder; é o perigo da legislação de classe; do governo que visa (com sucesso ou não), o benefício imediato da classe dominante, em perpétuo detrimento da massa. E uma das questóes que mais merecem consideração, quando se pretende determinar a melhor constituição de um governo, é como reunir precauções eficazes contra este mal. ${ }^{320}$

Dito isso, tenho uma boa e uma má notícias.

A má notícia (sempre opte por ela primeiro) é que essa transição não é alcançada de imediato, no curto-prazo, senão de forma gradual. Embora seja complicado perquirir objetivamente quando uma sociedade atinge um status superior de governança e controle, é certo que a mudança transcende ciclos políticos específicos ou condenações exemplares de corruptos notórios. É um trabalho de resiliência - da sociedade e dos líderes políticos.

A boa notícia é que essa transição é possível. Não obstante a maioria dos países que ostentam altos níveis de governança e controle da corrupção sejam favorecidos por fatores estruturais (tamanho reduzido, homogeneidade étnica, origem histórica etc.), há países que conseguiram reverter o ciclo e construir um contexto institucional virtuoso em período recente, limitando a corrupção e os favoritismos, como Chile, Uruguai, Geórgia, Estônia, Taiwan, Botswana e Coreia do Sul.

Vamos tratar, deste modo, das barreiras impostas pela sociedade para restringir as oportunidades de apropriação privada da coisa pública, a partir da consolidação de

320 MILL, John Stuart. Consideraçôes sobre o governo representativo. Brasília: Editora UnB, 1984, p. 68. 
um governo aberto, cujos pressupostos incluem a transparência, participação e a prestação de contas responsiva, para transformar o equilíbrio negativo em boa governança republicana.

Antes de adentrar nos aspectos mais específicos sobre tais dimensões, contudo, é necessário abordar a associação indispensável entre a governança aberta e os avanços tecnológicos verificados na última quadra do século, e a influência desta modernização no melhoramento dos contextos institucionais e na cultura política contra a corrupção. 
